\title{
Vida ribeirinha e currículo de Ciências: possibilidades em uma escola da Amazônia tocantina paraense
}

\author{
Riverside life and science curriculum: possibilities in a school in the \\ Amazon Tocantina Paraense
}

\author{
Edilena Maria Corrêa (edilenacorrea@yahoo.com.br) \\ Universidade Federal do Pará-Campus do Tocantins/Cametá (UFPA) \\ Maria dos Remédios Brito (mrb@ufpa.br) \\ Universidade Federal do Pará-Campus Belém (UFPA)
}

Resumo: Este estudo resulta de uma pesquisa de doutorado desenvolvida em uma escola ribeirinha do município de Cametá, Pará. O currículo de Ciências que se pontua na pesquisa vem pelas linhas menores, agenciado por potências vivas das vidas e de seus processos singulares que cruzam o ambiente escolar ribeirinho de uma comunidade da Amazônia tocantina paraense, argumentando que esse currículo é vida, embora esteja oficialmente nas malhas duras e sedentárias. A pesquisa buscou investigar sobre as potências de um currículo menor de Ciências para o alargamento das práticas educativas e as possibilidades dos modos de vida ribeirinhos em um currículo de Ciências. Objetivou-se compor, singularmente, esse currículo atravessado por saberes, fazeres e modos de vida dos estudantes ribeirinhos. Cruzada pelo pensamento teórico da Filosofia da Diferença deleuziana, por modos de variações e deslocamentos conceituais. A pesquisa entende que um currículo menor de Ciências atenta para as linhas da singularidade, como um programa de experimentação que atravessa a vitalidade de cada escola, professor e estudante, pois, um currículo é um modo de vida, de existência, um processo de produção e experimentação. Uma aposta nas aberturas das práticas curriculares de Ciências.

Palavras-chave: Currículo menor de Ciências. Vida ribeirinha. Escola ribeirinha.

\begin{abstract}
The study results from a $\mathrm{PhD}$ research developed in a riverside school in the municipality of Cametá-Pará. The science curriculum that punctuates in the research comes from the smaller lines, managed by the living powers of the lives and singular processes of those lives that cross the riverside school environment of a community in the Tocantina Paraense Amazon and, argues that the science curriculum is life, although officially be in the hard and sedentary meshes. The research sought to investigate the potentialities of a "minor curriculum" in science for the expansion of educational practices and the possibilities of riverside ways of life in a science curriculum. The
\end{abstract}


study aimed to compose, singularly, a science curriculum crossed by the knowledge, practices and ways of life of the riverside students. Crossed by the theoretical thinking of Philosophy of Deleuzian difference, by modes of variations and conceptual displacements. The research understands that a smaller science curriculum focuses on the lines of singularity, like an experimentation program that crosses the vitality of each school, teacher and student, because a curriculum is a way of life, of existence, a production process and experimentation. A bet on the openness of science curricular practices.

Keywords: Minor Science Curriculum. Riverside life. Riverside school.

\section{LINHAS DE ABERTURA}

Este artigo socializa parte de uma pesquisa de doutorado que envolveu experimentações curriculares em Ciências, traçadas pelas singularidades que povoam o território de uma escola ribeirinha na Amazônia tocantina paraense ${ }^{1}$. A pesquisa, finalizada em 2019, buscou pensar e experimentar um currículo de Ciências por escapes das formas dominantes, por processos menores no espaço escolar.

A pesquisa da tese, de cunho bibliográfico e de campo, envolveu atividades de experimentação com os estudantes a partir de seus saberes e modos de vida e teve como principal base teórica a Filosofia da Diferença, de Gilles Deleuze e Félix Guattari, com deslocamentos conceituais dos autores para pensar um currículo de Ciências por linhas menores na escola do campo, especificamente, no que diz respeito ao conceito menor abordado pelos autores na obra Kafka: por uma literatura menor (1977), além de outros estudiosos do campo do currículo, da educação em ciências e da educação do campo.

O interesse pelo currículo da escola do campo, mais especificamente na área de Ciências tendo como motor do pensamento os estudos de Deleuze e Guattari, são no sentido de pensar linhas e contornos curriculares por movimentos que problematizam as condições de invenção dos conhecimentos que se tornaram legítimos, das verdades

1 De acordo com Pereira (2014), Amazônia tocantina paraense é uma configuração territorial da Amazônia brasileira, que compreende atualmente os territórios constituídos em torno do eixo de circulação do rio Tocantins, abaixo da usina hidrelétrica instalada em Tucuruí, no Nordeste do estado do Pará, abrangendo municípios, como Baião, Cametá, Mocajuba, Igarapé-Miri, Limoeiro do Ajuru, Abaetetuba e Barcarena. 
universais que chegam nos pacotes e que desafiam a criar linhas de fuga por movimentos minoritários para escapar do aprisionamento e das certezas impostas pelas macropolíticas curriculares, que invisibilizam e silenciam outros saberes, como consta em Corrêa e Brito (2016; 2018).

Assim, o estudo objetivou compor, singularmente, um currículo de Ciências atravessado por saberes, fazeres e modos de vida dos estudantes ribeirinhos e teve como questões de investigação: quais as potências do conceito de menor para um currículo de Ciências de uma escola ribeirinha? $\mathrm{O}$ que podem as práticas minoritárias em um currículo de Ciências? É possível produzir um currículo menor, como modo de vida singular?

Para a construção desse artigo, utilizou-se o material produzido por meio da pesquisa bibliográfica e das atividades realizadas com os estudantes em sala de aula. Foi dada atenção especial aos saberes e modos de vida dos estudantes e sua relação com o currículo de Ciências. No artigo, priorizou-se uma escrita comprometida com um currículo de Ciências que possibilita vazões, fugas, resistências, formas de desvios de um currículo hegemônico já definido e indicado para ser servido na escola do campo.

\section{VIDAS RIBEIRINHAS NA AMAZÔNIA TOCANTINA PARAENSE}

A Amazônia, formada por povos que têm suas vidas tecidas a partir dos movimentos e envolvimentos com as águas dos rios, as matas e a terra apresentam singularidades que estão diretamente ligadas aos seus saberes. Uma das características da Amazônia é a comunidade ribeirinha ${ }^{2}$, que nasce e se desenvolve às margens dos rios e lagos, os ribeirinhos são homens, mulheres e crianças que têm suas vidas tecidas na relação com o rio, pois este está diretamente voltado à alimentação, ao transporte, ao lazer, à higiene e ao trabalho desses povos que nascem, vivem, existem, resistem e reexistem às margens dos rios. São os protagonistas das ações do cotidiano, das tessituras desse espaço sociocultural.

${ }^{2}$ O termo ribeirinho aqui se refere ao que é apresentado por Rodrigues (2008), utilizado na Amazônia para designar as populações humanas que moram à margem dos rios e que vivem da extração e manejo de recursos florestais aquáticos e da agricultura familiar. 
Como personagens conceituais - para usar o termo utilizado por Deleuze e Guattari (2010) no livro $O$ que é filosofia? - os ribeirinhos, nas adversidades enfrentadas no seu dia a dia, inventam suas saídas, criam suas linhas de fuga e ajudam a nutrir, potencializar e movimentar o pensamento rumo à construção e reconstrução do conhecimento. O rio envolve a vida e os percursos incertos no encontro com os presentes às suas margens. O movimento das águas possibilita às comunidades ribeirinhas encontros, relações e conexões que muitas vezes são invisíveis à organização do Estado.

Para Cruz (2008), os saberes dos ribeirinhos se expressam em diferentes aspectos de suas vidas e estão ligados às matas, à terra e à água, em meio às relações estabelecidas com os rios, a vida acontece. Nesse espaço de inundações, o domínio de determinadas questões é fundamental (conhecer e saber lidar com tempo e o movimento do rios), pois, do rio "depende a vida e a morte, a fertilidade e a carência, a formação e a destruição de terras, a inundação e a seca, a circulação humana e de bem simbólicos, a política e a economia, o comércio e a sociabilidade. O rio está em tudo" (LOUREIRO, 1995, p. 21).

São inúmeras as comunidades ribeirinhas que compõem esse complexo espaçotempo amazônico, que com suas forças criadoras buscam suas maneiras de existir, resistir, reexistir, por meio da afirmação de sua singularidade que implica em um devir, pois, "o eu que importa é aquele que está não por descobrir, mas por inventar [...]; não por explorar, mas por criar da mesma maneira que um artista cria uma obra, [...], tem que ser artista de si mesmo" (LARROSA, 2005, p. 76). Há sistemas de estratificação que tentam sempre estabelecer os papéis dos ribeirinhos, que definem uma identidade, que demarcam pontos, mas a singularização ribeirinha se move por entre pontos, vai de encontro às inúmeras tentativas de diminuição de suas potências pela vida, pela riqueza de seus espaços, de seus tempos, de seus saberes.

Os ribeirinhos põem-se no rio a remar, a andar descalços por entre os açaizeiros e cacaueiros, raízes e espinhos, atravessam rios e igarapés, caminham no chão de várzea. Nos muitos desafios da vida ribeirinha, nas redes que se tecem em meio a intensidades, encontros, o corpo ribeirinho vibra, torna-se território de saberes e fazeres do dia a dia em águas, terra e florestas, terrenos férteis de vitalidades. Avós, pais, filhos, estudantes...Compartilham encontros e experiências. 
Crianças e adolescentes ribeirinhos constroem um território de existência com adultos e idosos e, de forma individual ou coletiva, desenvolvem tarefas diárias de sobrevivência, imersas, também, em trocas afetivas onde encontram a própria força do aprender. Os aprendizados ocorrem em meio aos afetos, enquanto se convive com o outro. Uma comunidade ribeirinha é um lugar de vida que abre espaços para fluir, conectar-se por fluxos que fazem escapar ao já pensado, determinado, são campos invisíveis para experiências e pensamentos outros.

As residências, palafitas com traços distintos entre si, que de acordo com o gosto e situação financeira dos moradores, mostram suas mais belas e singulares maneiras de estar naquele ambiente. Os ribeirinhos carregam consigo todos os sentimentos que povoam aquele espaço, estão sempre em contínuo habitar: habitar espaços...Habitar corpos...Habitar sonhos para não perder suas potências e possibilidades de se reinventar.

\section{CURRÍCULO MENOR: PENSAR UM CURRÍCULO DE CIÊNCIAS NA ESCOLA RIBEIRINHA COM DELEUZE E GUATTARI}

Há um preceito que abraça o currículo de Ciências, que indica os caminhos retos ao professor, e de acordo com Deligny (2015, p. 50), "há sempre, em algum lugar, ninguém sabe onde, uma alta corte que nos observa do ponto de vista do correto", e, diariamente, se é desafiado a enfrentar e resistir a esse currículo reto, ajuizado, que pensa pela homogeneidade, pela hierarquia, e experimentar outras formas de currículo que passe pelo corpo, pelas forças e pelas potências dos modos de vida.

Resistir às orientações dos caminhos retos, que dizem como deve ser um bom currículo e uma boa aula de Ciências, para produzir currículo em meio a encontros que mobilizam, que potencializam, que emanam da vida, do movimento, das afecções, tem sido um tanto desafiador. Todavia, segundo Carvalho e Rangel (2013), produz-se currículo em meio a encontros potencializados por múltiplos afetos e por informações compartilhadas, nesse sentido, os documentos e propostas curriculares devem ser visualizados como textos que se entrelaçam a outros textos (escritos, orais, imagéticos, sonoros) e não como caminhos retos a seguir. A pesquisa realizada sobre um currículo de Ciências em uma escola ribeirinha traçou linhas de resistência, criação e experimentação por meio de práticas minoritárias. 
Foram feitas incursões pelo pensamento de Gilles Deleuze e Félix Guattari no que diz respeito ao campo curricular, especificamente a partir da obra Kafka: por uma literatura menor. Nela, os autores abordam o conceito menor como possibilidade de desterritorialização do já instituído, imposto. Na desterritorialização que Kafka faz da língua, está expressa a ruptura de seu compromisso nato com as ideologias da língua materna, desse modo, o conceito menor trazido pelos autores, ajuda a pensar possibilidades de desterritorializar, romper com o compromisso com uma grade curricular de Ciências na escola do campo e, experimentar um currículo que não esteja comprometido com as formatações e "verdades" já impressas de antemão. "Verdades" que dizem com que e com quem o currículo está comprometido. Na referida obra, os autores abordam o conceito de literatura menor envolvendo três características, quais sejam: a desterritorialização, a ramificação política e o valor coletivo. Tais características são importantes para pensar a questão curricular em Ciências na escola do campo através de deslocamentos e recriações.

A primeira característica apresentada pelos autores sobre a literatura menor, a qual possibilita deslocar para se pensar em um currículo de Ciências na escola ribeirinha, é a desterritorialização. Nesse sentido, um currículo maior estaria ligado a uma territorialidade, a um modelo, no qual, padrão, seria o currículo oficial. Um currículo menor seria a fuga dessa norma, o desvio que uma minoria faz dentro do currículo maior, pois, "uma literatura menor não é a de uma língua menor, mas antes o que uma minoria faz em uma língua maior” (DELEUZE; GUATTARI, 1977, p. 25).

Contudo, vale ressaltar que pensar um currículo de Ciências por vias menores não significa renunciar ou negar o currículo maior/oficial, mas criar, adotar currículos das minorias. Seria diferenciar o currículo menor fazendo dele um uso menor. Desterritorializar o currículo maior de Ciências na escola do campo, nesse sentido, seria escapar do território padronizado, normatizado, que diz o que é correto ou legítimo ensinar de Ciências, e buscar criar deslizamentos, linhas de fuga que vislumbrem outras possibilidades para "ir sempre mais longe na desterritorialização".

Sobre a segunda característica de uma literatura menor, Deleuze e Guatarri (1977) destacam que o individual é ligado imediatamente à política. $\mathrm{O}$ caso individual se torna então mais necessário, indispensável, na medida em que outra história se agita nele (DELEUZE; GUATTARI, 1977). Nesse sentido, cada caso constitui uma singularidade, 
que remete a um imediato político, a um ato de resistência. Nessa perspectiva, segundo os autores, há outra história agitando-se na literatura menor. No caso de Kafka, trata-se de conflitos que são singulares e, ao mesmo tempo, é também de todo um povo, o que para Deleuze e Guatarri (1977) é visível na escrita do autor, um judeu de Praga, que só pode escrever em alemão, uma escrita que subverte a literatura maior.

Assim, também, há outras histórias pulsando em um currículo de Ciências. Um currículo menor resulta de um ato político do professor na sala de aula, possibilita ver outras histórias, outras experiências, outros saberes que são silenciados, negligenciados no currículo oficial. Há muitas outras histórias que agitam o currículo de Ciências e um currículo menor cria outras possibilidades que emergem do currículo proposto pelas diretrizes. Nesse sentido, um currículo menor opera por atos de resistência, e cria outros currículos dentro dos Parâmetros, das Diretrizes Curriculares Nacionais. Nesse ato de criação, desterritorializa as diretrizes do currículo maior e possibilita que o educador militante exerça suas ações em nível micropolítico.

Como ato político, um currículo menor, seria um currículo que permite atravessamentos, não comportando mais sentido único em relação a conteúdos, metodologias, avaliação, torna-se um campo de contingências. Nele não há fronteiras, mas dobras movediças, com inúmeras possibilidades. Paraíso (2009) ressalta que um currículo está sempre cheio de ordenamentos, de linhas fixas, de corpos organizados, de identidades majoritárias. Porém, ele também está sempre cheio de possibilidades de rompimento das linhas do ser; de construção de modos de vida, pois é um artefato com muitas possibilidades de diálogos com a vida; com diversas possibilidades de modos de vida, de povos e de seus desejos.

O valor coletivo é a terceira característica que os autores trazem na literatura menor, Deleuze e Guatarri (1977) destacam que em uma literatura menor, o individual cede lugar ao coletivo, nesse sentido, tudo adquire esse valor. Desse modo, em um currículo menor, não há lugar para o solitário, o isolado, pois toda a ação educativa implica muitos indivíduos. Em uma sala de aula, em uma aula de Ciências, portanto, não há saberes isolados, há agenciamentos coletivos. Assim, um currículo dessa área, na escola do campo, se tece em meio a muitos encontros, desejos e intensões de estudantes e professores. Todavia, o peso dos resultados mensuráveis e a excessiva confiança nas "reformas curriculares" e orientações delas advindas, ignora a coletividade, a 
singularidade, a problematização e experimentação dos professores e estudantes no cotidiano escolar nas aulas de Ciências.

Pensar um currículo de Ciências na escola ribeirinha por meio do conceito de minoração abordado por Deleuze e Guattari (1977), como desterritorialização3, resistência, ato político e coletivo, implica tomá-lo pelo jogo do devir, permitindo outros movimentos no currículo e no ensino de Ciências.

\section{POSSIBILIDADES NO CURRÍCULO DE CIÊNCIAS EM UMA ESCOLA RIBEIRINHA: ENTRE MARGENS E MAPAS}

A realidade educacional brasileira ainda denuncia que o campo é o lugar onde estão os maiores índices de pessoas não alfabetizadas, escolas com infraestrutura precária, altas taxas de exclusão escolar e currículos que não consideram os saberes locais (HAGE; CRUZ 2015). E é neste contexto que pensar o ensino de Ciências nas escolas do campo é, antes de tudo, pensar os sujeitos em seus espaços de luta pela vida, pelo trabalho, pela dignidade, pela construção de um projeto de educação para que professores e estudantes, em seus processos formativos, reflitam e criem formas de empoderamento e resistência, sendo " construtores de conhecimentos" (OLIVEIRA; GONÇALVES, 2016, p. 17).

Traçar mapas que tenham como referências de localização os ribeirinhos, que se movimentam em rios, e em seus modos de vida como as águas, que não têm uma forma e nem um lugar fixo, mais que ver e sentir uma ilha, implica localizar uma escola, estudantes, professores, pais, comunidade, deslocar-se por lugares, pelas singularidades e potencialidades ribeirinhas que por seus saberes e fazeres estão em constante refazer-se, em movimentos que desdobram em arranjos que ajudam a compor um currículo. Mapear o contexto de vida desses estudantes tem importância no que diz respeito aos atos de criação, composição, experimentação, movimentos em

30 termo desterritorialização aqui se refere ao que Deleuze e Guattari (2009) tratam como o movimento pelo qual se abandona o território. Aqui, pensa-se no currículo hegemônico como o território a ser abandonado, pelo movimento de desterritorialização que produz linhas de fuga, escapes das linhas segmentárias, linhas duras do currículo. 
um currículo que vive em meio às dinâmicas sociais, culturais, políticas, econômicas...Ribeirinhas.

Na obra Mil Platôs, Deleuze e Guattari (2005) trazem a noção de mapa como forma de pensar por aberturas, como possibilidade de reverter o pensamento que se funda no pensamento arbóreo, centrado, no que diz respeito à produção do conhecimento, e concebem a noção de rizoma como possibilidade de pensar a partir de conexões, dessa forma, um currículo de Ciências de uma escola pode ser composto por descentramentos e aberturas, como um campo em fluxos contínuos, como 'riacho sem início nem fim, que rói suas duas margens e adquire velocidade no meio' (DELEUZE; GUATTARI, 2005, p. 36).

O mapa é aberto, é conectável em todas as suas dimensões. Ele pode ser rasgado, revertido, adaptar-se a montagens de qualquer natureza, ser preparado por um indivíduo, um grupo, uma formação social. [...], mapa que deve ser produzido, construído, sempre desmontável, conectável, reversível, modificável, com muitas entradas e saídas (DELEUZE; GUATTARI, 2005, p. 21).

Os mapas dos espaços ribeirinhos ajudam a indicar a dinâmica que envolve esse lugar. Nele cabem água, terra, vidas, modos de vida de um povo que ali existe e resiste. Vidas que se movimentam em um lugar onde o rio não é o que corre, mas o que ao mesmo tempo gira em torno de tudo e tudo gira em torno dele. Rio onde a vida acontece sempre em conexões.

Deligny (2015), em sua experiência com crianças autistas em Cévennes, usava os mapas dos trajetos, gestos e acontecimentos como possibilidade de alargamento do olhar do adulto em relação às crianças, de atentar para desvios, erros, aproximação e afastamento de lugares e objetos observados no dia a dia das crianças.

\footnotetext{
Mapas da realidade vivida pelas crianças e jovens, cartografia de como essa realidade poderia estar presente nos processos vivenciados dentro das instituições, mapas de criação de possibilidades para que as crianças e os jovens pudessem se localizar, criar pontes para tomada de iniciativas. [...]. Produzir mapas foi uma forma de criar desvios em relação aos valores vigentes (REZENDE, 2016, p.140).
}

O estudante ribeirinho é uma composição que se tece no dia a dia em diferentes e singulares espaços (rio, floresta, escola...) e o mapa é um modo de traçar esses lugares e corpos que se atravessam e possibilita olhares sensíveis aos modos de vida dos estudantes ribeirinhos, esses que são inventores de seus próprios mapas. 
Nesta pesquisa, os mapas constituíram-se como importante ferramenta para conhecer os diversos espaços por onde os estudantes ribeirinhos transitam, por onde seus corpos atravessam e se deixam atravessar, procurando fugir de um currículo pronto. Traçar mapas possibilitou fugir dos métodos e operar por desvios. O mapa descreveu lugares, movimentos e a relação dos estudantes com esses lugares.

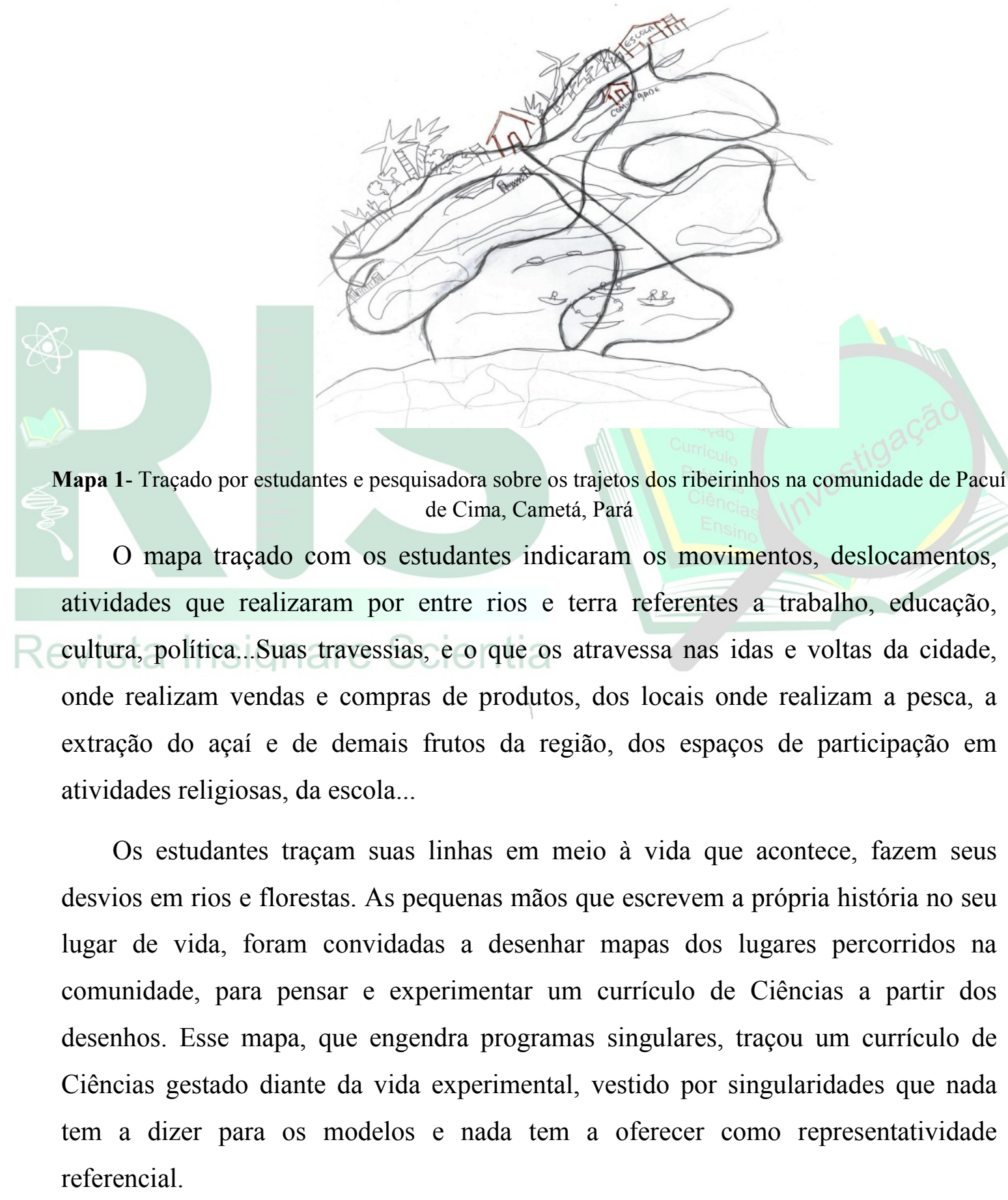


O mapa dos trajetos e das experiências dos ribeirinhos indicaram que se aprende a pescar pescando, aprende-se a técnica de apanhar o açaí subindo nas árvores, aprende-se a nadar nadando. Foi possível falar dos domínios dos exercícios, das experiências que dizem respeito a cada um e de suas relações com os movimentos da água, com as dinâmicas dos rios, com as diversas vidas que compõem a fauna e a flora daquela comunidade ribeirinha.

Mapa que possibilitou "trair" o currículo oficial, que permitiram outros movimentos e aberturas no currículo de Ciências pela experimentação de saberes outros. Trair tem relação direta com a experimentação. Trair a lição do livro didático, a teoria que diz como pensar, como fazer, o currículo que diz o que é legítimo, o que é válido para ser ensinado em Ciências na escola do campo. Trair a disciplina que impõe o gesto duro do corpo, assim como o método. Trair a si mesmo, ser subversivo, resistir.

Valorizar a ignorância na experimentação do programa singular do currículo menor, pois ele se coloca como resistência propulsora do conhecimento. Não é uma ignorância à espera de, mas aquela que sabe que não sabe e vai com o corpo aberto ao novo, vai encontrar suas misturas. É um programa experimental e vital, tendo a Escola como uma das condições da experiência e não sendo o condicionamento da experiência. Táticas de fuga podem ser engendradas.

O mapa traçado ganhou força a partir de seu compartilhamento, de suas linhas movidas pela história e geografia ribeirinha. A história, que foi traçada por todos os estudantes, envolveu os deslocamentos nos modos de vida de um povo. O mapa registrou com traços de trajetos e movimentos, o que os ribeirinhos realizam em seus espaços e possibilitou conhecer e acompanhar os movimentos dos estudantes, permitindo outras maneiras de olhar, sentir, pensar, experimentar um currículo de Ciências.

O mapa da vida dos estudantes ribeirinhos, com indicação de ambientes e de seus movimentos na comunidade, não deve servir para pensar um currículo dentro da Escola e outro fora, pois a vida não obedece a tais delimitações, ela acontece no lugar onde não há fronteiras, logo, não há espaço para traçar os limites, mas as múltiplas conexões que envolvem a vida ribeirinha. Ele possibilita olhar por outras lentes, permite ver os 
estudantes ribeirinhos por suas singularidades. Mapa que não é mera transcrição do espaço ribeirinho. Aqui ele serve de desvio, um meio para uma desterritorização de um currículo de Ciências territorializado, um experimento que envolve o corpo, que permite localizar os movimentos que os ribeirinhos realizam, seus modos de vida, o que os atravessa fora da Escola, o que os afeta que pode ser conectado com a Escola, com o currículo.

Esse "mapa de movimentos" descreveu singularidades e ajudou a ver diversos elementos e espaços ribeirinhos que compõem a vida dos estudantes, suas presenças e relações nos diversos espaços da comunidade e que extrapolam os espaços da ilha onde residem. As linhas correspondem ao percurso pelo rio que, frequentemente, os estudantes realizam para chegarem à escola, elas compõem os estudantes ribeirinhos, “como diz Deligny, essas linhas nos compõem, assim como compõem nosso mapa. Elas se transformam e podem mesmo penetrar uma na outra. [...]" (DELEUZE; GUATTARI, 1996, p. 77).

Traçados que indicaram rios e trajetos que compõem a vida dos estudantes, seus movimentos na comunidade em que vivem, lugares pelos quais percorrem e desenvolvem atividades e mostram que eles não estão isolados na escola, isso tem importância para pensar um currículo de Ciências em perspectivas menores, um currículo que atente para a rede em que os estudantes estão envolvidos.

O mapa dessa rede de vida é um convite a olhar e experimentar um currículo outro a partir das linhas traçadas e percorridas pelos estudantes ribeirinhos. Ele não mostra um currículo de Ciências montado, estruturado, mas as potências curriculares dos diversos espaços por onde os estudantes transitam, as relações dos estudantes com os espaços, como eles habitam e as pistas para pensar e experimentar novas práticas curriculares.

\section{PELOS FIOS DA VIDA RIBEIRINHA, UM CURRÍCULO DE CIÊNCIAS MENOR EM TESSITURAS}

De maneira geral, no currículo e no ensino de Ciências há um fio dourado que tenta, a todo instante, ofuscar os fios da potência criativa, da singularidade, fios que tecem a vida, o corpo dos sujeitos do campo em suas lutas diárias. Porém, há linhas de resistências no currículo da escola do campo, linhas que tecem processos criativos, que 
possibilitam que outros currículos de Ciências sejam traçados pelas margens, com as singularidades, saberes e modos de vida do povo campesino.

Para Silva (1996), o currículo não é campo de transmissão, absorção passiva de cultura absorvido, mas de ativa criação, recriação, contestação e transgressão. Dessa maneira, compreende-se que o currículo de Ciências da escola ribeirinha precisa ser pautado na produção do conhecimento a partir das relações do sujeito com o meio onde vive, pois, de acordo com Caldart (2004, p. 110), a estrutura pedagógica da escola do campo "desrespeita ou desconhece a sua realidade, seus saberes, suas formas de aprender e ensinar". Assim, ensinar e aprender Ciências no campo a partir das experiências, modos de vida e cultura dos sujeitos torna-se necessário não apenas sob o ponto de vista do conhecimento científico, mas de melhoria de vida, de tomadas de decisões e posicionamentos críticos diante de questões de relevância social, política, ambiental, ecológica, econômica, cultural, de saúde pública, enfim, questões que envolvem a vida dentro e fora da escola.

Krasilchik e Marandino (2004) ressaltam que é importante ampliar as oportunidades de acesso e produção de significados sobre o conhecimento científico pela população, desse modo, torna-se fundamental que o currículo de Ciências da escola do campo dê significados aos conceitos científicos a partir da realidade vivenciada pelos estudantes. No campo da educação em ciências, a concepção a respeito da ciência tem sido de uma visão racionalista, neutra, positiva, o que tem contribuído não só para reafirmar determinados saberes como legítimos no currículo, como para silenciar outros. Para Pietrocola (2013), a ciência na escola poderia privilegiar a imaginação, a criação, porém, limita-se à memorização e reprodução de conceitos, fórmulas, símbolos. Dessa forma, há uma dura separação entre atividades de raciocínio e atividades de imaginação.

Encontros dos estudantes com lugares capazes de gerar microfissuras no currículo de Ciências, por onde pode pulsar a vida. Ambientes entre rios, florestas, elementos, corpos que se atravessam, atravessam e avançam os limites do currículo servido na escola. Os estudantes ribeirinhos em atividades realizadas no decorrer da pesquisa, mostraram que há um currículo não saciado pelo esquadrinhamento das linhas da escola. 
A imagem abaixo resulta de uma atividade sobre teia alimentar aquática. Os estudantes, com seus saberes, traçaram as relações que conhecem entre as vidas aquáticas. As diversas espécies identificadas na imagem pelos discentes, assim como suas relações de umas com as outras, mostram que há muitos saberes às margens do currículo livresco. São vidas e relações que fazem parte do cotidiano dos estudantes, são peixes e crustáceos que constituem a base alimentar dos sujeitos que residem na comunidade. Aqui, um currículo de Ciências vivo transversaliza com a vida e com os saberes dos estudantes.

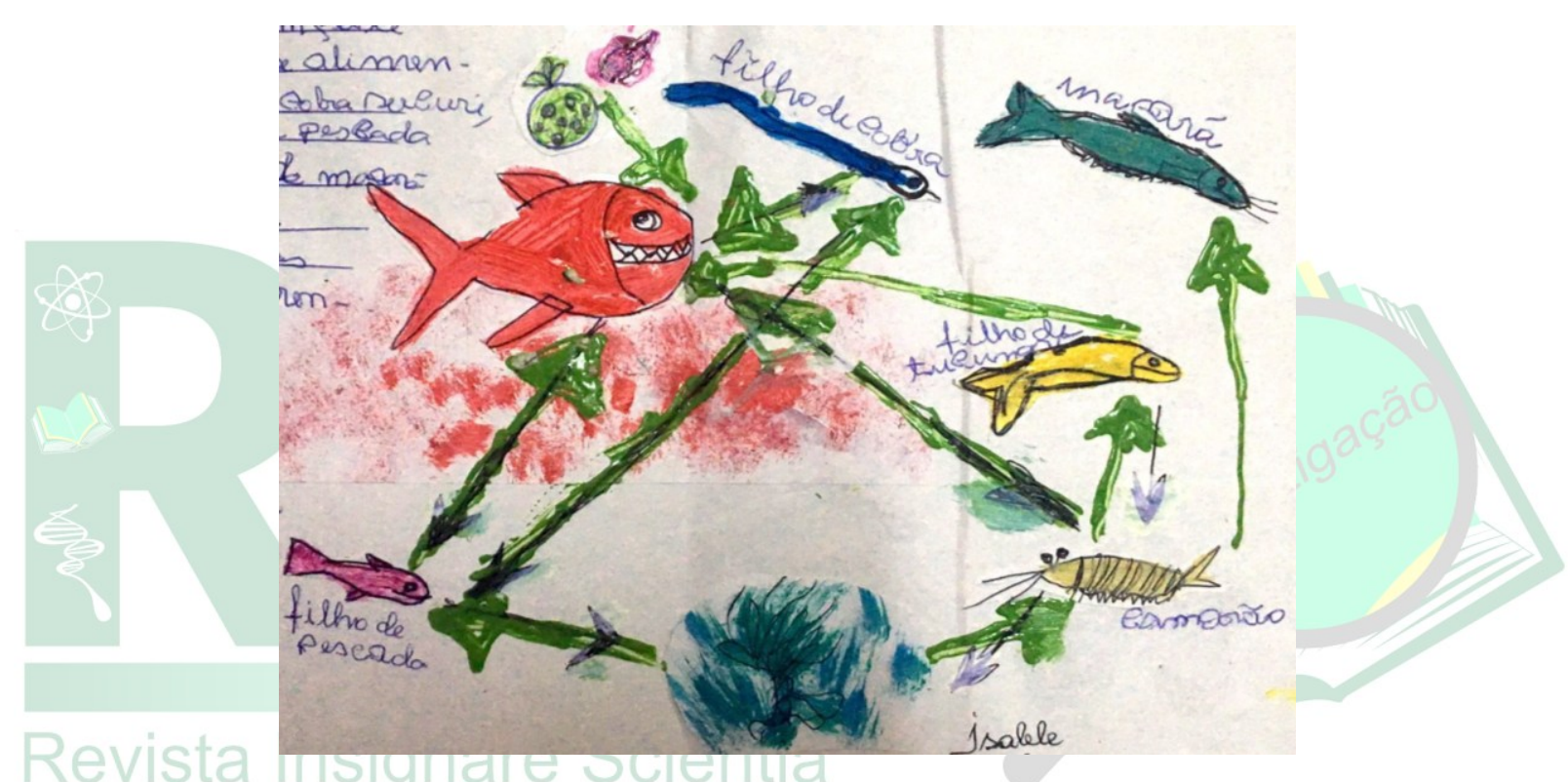

Figura 1 - Teia alimentar aquática traçada por uma estudante riberinha

Em seus desenhos, pinturas e relatos realizados durante as aulas, os estudantes expuseram seus encontros vitais com os elementos e as vidas que os cercam e que potencializam o currículo de Ciências. Encontros com raízes (que auxiliam no controle dos processos de erosão na comunidade ribeirinha); com peixes (que por meio de seus apetrechos de pesca e das práticas de captura aprendem formas de identificar e caracterizar espécies, seu nicho ecológico e habitat); com o solo (que por meio da sua textura, cor e localização, indicam sua potencialidade fértil) e com a água (que pelos movimentos das marés, associados às fases da lua, definem os períodos mais propícios à pesca, à caça, ao plantio, à colheita).

Vidas e elementos que embora pareçam sedimentados pelo imaginário como elementos fixos, isolados, apartados e de qualquer relação com o currículo de Ciências, 
estão entranhadas nos estudantes, na comunidade onde a escola se faz presente. São seus saberes e seus modos de vida que potencializam e possibilitam um currículo menor. Não há como isolar a vida dos ribeirinhos do currículo da escola. Rosa e Robaina (2020, p. 158), ressaltam que "o ensino nas Escolas do Campo deve ter a intenção de exercitar o convívio com as atividades do meio em que nossos educandos vivem, conhecer esse meio e valorizá-lo".

No contato com o rio, a água se torna pele; no encontro/relação entre criança e árvore, a vida é vista sem hierarquia de importância; nas especificidades das práticas de pesca e de acordo com os saberes dos pescadores, as espécies de pescados são identificadas e classificadas...Nos encontros entre ribeirinhos e demais vidas e elementos, os estudantes ribeirinhos constroem outros corpos, outras relações, outras possibilidades.

De algumas atividades/registros dos estudantes, frutos de suas vivências, um universo curricular está a saltar. Que potências curriculares podem irromper de registros, cujo olhar e mãos infantis mostram seus saberes/fazeres no interstício da escola? Quando em uma curta e simples explicação de um aluno sobre a técnica de matar uma árvore pela remoção das camadas de suas cascas, o que a botânica do currículo já traçado tem a dizer à botânica do dia a dia dos estudantes ribeirinhos?

São saberes que fazem deslocar as linhas fixas de um currículo já pensado e estruturado, pronto para ser servido. Os corpos ribeirinhos deslocam os corpos curriculares constituídos e cobertos por conteúdos e mecanismos prescritos e constroem outras possibilidades no currículo de Ciências. Não são os lugares ou os elementos ribeirinhos em si que interessam, mas o que elas expõem, o que está além de uma identificação ou classificação da ciência, as afetações que ultrapassam a fronteira científica.

Quando se vê pequenos e atentos olhos perderem-se a olhar pela janela da sala de aula um fruto na árvore, percebe-se que esse olhar fala, sente...São vidas que se entrelaçam. Criança, árvore e fruto crescem juntos e essas vidas se tecem em meio à água, ao vento, à terra...Sem hierarquia de importância. Há uma árvore que cresce e frutifica em conexão com o atento e sensível corpo infantil ribeirinho e que precisa compor o corpo curricular de Ciências da escola ribeirinha. 
Com as atividades realizadas a partir das experiências e modos de vida dos estudantes ribeirinhos, entende-se o quanto é importante apostar nos encontros com lugares que dizem sobre os seus modos de vida como forma de potencializar um currículo de Ciências que não se resuma a olhar e explicar a vida da floresta dentro do mundo, a planta dentro da vida, a espécie dentro da planta, o exemplar dentro da espécie. Há importância também nas relações, nas afetações entre esses exemplares e outras vidas/elementos.

Como explicar em uma aula de Ciências, a um estudante ribeirinho (que faz a extração do cacau, do açaí), sobre a vida dos vegetais, sem que seja tocado na relação de vida do estudante com esse vegetal? Em um currículo de Ciências, o fio brilhante da ciência não pode ofuscar o fio da vida, da docência e os demais fios que tecem as relações com o mundo. A vida não se fixa a conceitos e classificações científicas, e o mundo não está separado em organismos vivos e não vivos, ele é relação entre elementos e seres, encontros. Os espaços e modos de vida dos ribeirinhos são possibilidades de cultivar um olhar singular no currículo de Ciências.

A vida parte das afetações, do sensível, não do científico, Ingold (2015) ressalta que as vidas humanas e não humanas não estão fechadas para o mundo, mas abertas, como uma linha em devir. Ainda segundo o autor, organismos e coisas habitam um mundo aberto em permanente construção, em um entrelaçamento de linhas de vida em um espaço fluido onde o ser vivo se movimenta, afetando e sendo afetado pelo mundo que também está em pleno movimento.

A vida é tecida em meio aos lugares, assim como os lugares são tecidos em vida, em um processo contínuo e interminável de atravessamentos e afetações. Os espaços de vida ribeirinha, seus saberes, fazeres, movimentos, são recursos e potências capazes de efetuar desterritorializações no currículo de Ciências e possibilitar outros olhares nos processos de ensinar e aprender ciências. Ver os estudantes ribeirinhos por seus saberes e experimentações com o que os toca, com o que os afeta, com o que os atravessa implica valorizar "a importância dessa percepção do outro como alguém que experimenta e explora o conhecimento de diferentes formas" (TENÓRIO et al. 2019, p. 166). 
Andar na terra-céu-tempo-vento é considerado por Ingold (2015) como a forma primordial que os seres vivos habitam a terra, traçando em seus passos as linhas de seu próprio movimento. Dessa forma, o mundo onde a vida se dá nos movimentos e caminhadas se estruturaria em uma espécie de malha relacional resultante da correspondência entre os movimentos das linhas de vida ao longo dos caminhos.

Olhar o mundo a partir da perspectiva de uma malha relacional, onde tudo se relaciona, implica soltar o currículo das amarras que impedem tal relação, por exemplo, da exigência de ensinar e aprender sobre a vida apenas por especificidades, características anatômicas e fisiológicas de cada ser vivo como a ciência legítima. É preciso atentar para as afetações dos corpos ribeirinhos, para suas relações de vida e, assim, movimentar as linhas duras do currículo de Ciências de uma escola ribeirinha, abrir fissuras para muitos outros currículos na imanência desses entrelugares, pois, "o que conta é o que passa no meio. Sempre no meio." (CORAZZA; SILVA, 2003, p. 66).

\section{ALGUMAS CONSIDERAÇÕES}

Partir da ideia de currículo como algo que se constitui na experiência, significa compreendê-lo para além da formalidade, das rotinas empreendidas nas escolas, pois para além de projetos, conteúdos e disciplinas existem sujeitos que produzem saberes. Nesse sentido, o currículo requer vivência, conforme afirma Larrosa (2002), com o que acontece, com o que se passa, com o que toca, mas fundamentalmente com o que nos acontece, com o que nos passa, com o que nos toca.

Os currículos vivem nas relações intra e extraescolares, se constituem nos movimentos que atravessam as vidas dos estudantes, dos professores, da comunidade escolar e da comunidade onde a escola está inserida. Eles se fazem de multiplicidades, dos muitos presentes em cada um e nas relações. Não há como ser pensado e tomado como um dado pronto e acabado, ele é algo fabricado, inventado, negociado cotidianamente.

Entende-se que a possibilidade de pensar um currículo como um campo imanente está em perceber que ele se produz no espaço da sala de aula, em fluxos, movimentos, transversalidade de saberes. Pode ser produzido num espaço-tempo de criação, de (re)invenção, atravessado por linhas menores, como ato político que acontece no cotidiano das escolas, nos encontros de professores e estudantes, acompanhando a potência criadora dos saberes, aberto a novos acréscimos. 
Teria o currículo uma perspectiva política no que tange ao papel do professor Comprometendo-se com as multiplicidades, com a diferença, um currículo menor caracterizado pelas ações políticas do professor no dia a dia da escola. Experimentar práticas minoritárias no currículo de Ciências implicou criar movimentos de escapes e desvios das formas dominantes por processos menores no espaço escolar, escape das macropolíticas que mortificam, engessam o currículo.

Experimentar aulas de Ciências a partir dos modos de vida, traçar outros currículos a partir da vida que acontece em rede, que se tece junto, apostar nas potencialidades das práticas minoritárias, assumindo sua marginalidade em relação aos papéis representativos do currículo, foi importante como ato de subversão às perspectivas representacionais de um currículo hegemônico, excludente, que negligencia e silencia para assumir o lugar da diferença, da singularidade, da vida.

Entende-se que um currículo de Ciências menor caracteriza-se por sua potência de desterritorialização dos saberes majoritários, pela criação por meio das vidas, desejos, saberes ribeirinhos marginalizados pela escola, em uma conexão do individual com o político, como ato político e ressalta-se que as práticas minoritárias aqui abordadas, não têm nenhuma ligação com o que seja pequeno, inferior, vulgar, ao contrário, nelas são possíveis as potências menores das existências, são possíveis que a multiplicidade seja visível, experimentada como um ato de direito, de ética e de política.

\section{REFERÊNCIAS}

CALDART, R.S. A escola do campo em movimento. In: ARROYO, M.G.; CALDART, R.S.; MOLINA, M. (org.). Por uma educação do campo. Petrópolis: Vozes, 2004.

CARVALHO, J.M.; RANGEL, I.S. Currículos, multidão e políticas de narratividade. In: FERRAÇO, C.E.; CARVALHO, J.M. (Org.). Currículos, pesquisas, conhecimentos e produção de subjetividades. Petrópolis: De Petrus; Vitória: Nupec/Ufes, 2013.

CORAZZA, S.M; SILVA, T.T. Composições. Belo Horizonte: Autêntica, 2003.

CORRÊA, E.M.; BRITO, M.R. Currículo menor em Ciências: entre forças, desejos e vidas ribeirinhas na Amazônia tocantina. Revista da SBEnBIO, n. 9, 2016.

CORRÊA, E.M.; BRITO, M.R. Potências do conceito de currículo menor para o ensino de ciências de uma escola ribeirinha na Amazônia tocantina. Linha Mestra, n. 35, 2018. Disponível em: http://alb.org.br/revista-linha-mestra-no-35/. Acesso em: 13 nov. 2018 . 
CRUZ, V.C. O rio como espaço de referência: reflexões sobre a identidade ribeirinha na Amazônia. In: TRINDADE JÚNIOR, S.C.C.; TAVARES, M.G.C. (Org.). Cidades ribeirinhas na Amazônia: mudanças e permanências. Belém: EDUFPA, 2008. p. 4967.

DELEUZE, G.; GUATTARI, F. O que é a Filosofia? São Paulo: Editora 34, 2010.

DELEUZE, G.; GUATTARI, F. Mil platôs: capitalismo e esquizofrenia. São Paulo: Ed. 34, 2009. v.1.

DELEUZE, G.; GUATTARI, F. Mil platôs: capitalismo e esquizofrenia. v. 1. São Paulo: Ed. 34, 2005.

DELEUZE, G.; GUATTARI, F. Mil Platôs: capitalismo e esquizofrenia. São Paulo: Editora 34, 1996. v. 3. p. 31-62.

DELEUZE, G.; GUATTARI, F. Kafka: por uma literatura menor. Rio de Janeiro: Imago, 1977.

DELIGNY, F. O aracniano e outros textos. Tradução: Lara de Malimpensa. São Paulo: n-1, 2015.

HAGE, S.A.M.; CRUZ, C.R. Movimento de educação do campo na Amazônia paraense: ações e reflexões que articulam protagonismo, precarização e regulação. In: $37^{\mathrm{a}}$ REUNIÃO NACIONAL DA ANPED, 2015, Florianópolis. Anais [...]. Florianópolis: UFSC, 2015.

INGOLD, T. Estar vivo: ensaios sobre movimento, conhecimento e descrição. São Paulo: Vozes, 2015.

KRASILCHIK, M.; MARANDINO, M. Ensino de Ciências e Cidadania. São Paulo: Moderna, 2004.

LARROSA, J. Nietzsche e a Educação. Belo Horizonte: Autêntica, 2005.

LARROSA, J. Notas sobre a experiência e o saber da experiência. Revista Brasileira da Educação, Rio de Janeiro: ANPED, n. 19, 2002. Disponível em:

http://www.anped.org,br/rbe/rbedigital/RBDE19/RBDE19_04_LARROSA_BONDIA.P DF. Acesso em: 5 jul. 2020.

LOUREIRO, J.J.P. Cultura Amazônica: uma poética do imaginário. Belém: CEJUP, 1995.

LOUREIRO, J.J.P. Porantim: obras reunidas. v. 1. São Paulo: Escrituras, 2000. p. 23 96. 
OLIVEIRA, E.S.; GONÇALVES, T.V.O. O ensino de ciências no contexto da educação do campo. In: OLIVEIRA, E.S.; GHEDIN, E. Ensino de ciências: alternativas metodológicas na educação do campo. Boa Vista: EdUFRR 2016.

PARAÍSO, M. Currículo, desejo e experiência. Educação e Realidade, Porto Alegre, v. 34, n. 2, p. 277-293, 2009. Disponível em:

www.seer.ufrgs.br/educacaoerealidade/article/download/9355/5545. Acesso em: 18 dez. 2018.

PEREIRA, Edir A. Dias. As encruzilhadas das territorialidades ribeirinhas: transformações no exercício espacial do poder em comunidades ribeirinhas na Amazônia tocantina paraense. Niterói, 2014. 434f. Tese (Doutorado em Geografia) Universidade Federal Fluminense, 2014. Disponível em:

https://www.capes.gov.br/images/stories/download/pct/mencoeshonrosas/227947.pdf. Acesso em: 13 de março de 2018

PIETROCOLA, M. Curiosidade e imaginação: os caminhos do conhecimento nas ciências, nas artes e no ensino. In: CARVALHO, A.M.P. (Org.). Ensino de ciências: unindo a pesquisa e a prática. São Paulo: Cengage Learning, 2013.

REZENDE, N.C. Do asilo ao asilo, as existências de Fernand Deligny: trajetos de esquivas à instituição, à lei e ao sujeito. Rio de Janeiro: Pontifícia Universidade Católica do Rio de Janeiro, 2016.

ROSA, Sabrina Silveira da. ROBAINA, José Vicente Lima. O Ensino de Ciências nas Escolas do Campo a partir da análise da produção acadêmica. Revista Insignare Scientia -RIS, v. 3, n. 2, 18 jun. 2020.

SILVA, T.T. Identidades terminais: as transformações na política da pedagogia e na pedagogia da política. Petrópolis: Vozes, 1996.

TENÓRIO, W. D.; FORMIGOSA, M. M..; ROCHA, C. G. S.; SANTANA. R. H. A formação e atuação docente na disciplina de ciências em escolas do campo na Amazônia paraense. Revista Insignare Scientia -RIS, v. 2, n. 4, 19 dez. 2019. 